\title{
Compulsory psychiatric treatment of inmates in prisons in Russia Dmitry Malkin
}

\author{
Address: Serbsky Center for Social and Forensic Psychiatry, 23 Kropotkinsky Per., 19992 Moscow, Russia (Russian Federation) \\ from WPA Thematic Conference. Coercive Treatment in Psychiatry: A Comprehensive Review \\ Dresden, Germany. 6-8 June 2007 \\ Published: 19 December 2007 \\ BMC Psychiatry 2007, 7(Suppl I):P22 doi:10.1 I86/I47I-244X-7-SI-P22
}

This abstract is available from: http://www.biomedcentral.com//47I-244X/7/SI/P22

(C) 2007 Malkin; licensee BioMed Central Ltd.

According to article 99 of the Criminal Code of the Russian Federation those persons who are imprisoned for different crimes but at the same time suffer from psychiatric disorders may receive compulsory treatment by the decision of the court. It is necessary to emphasize that these psychiatric disorders are not serious and that is why they do not exclude responsibility for the crimes committed. Thus, alongside with the punishment these inmates are appointed to receive compulsory outpatient treatment and supervision. There are 3 stages of this kind of treatment. At the first stage, which is called adaptation and the duration of which is usually one month, the doctors use correctional methods aimed at adaptation, reduce symptomatology of psychogenic disorders, and treat somatic pathology. Within the second stage complex treatment is used (psychotherapy, psychopharmacology, so called social measures of treatment aimed at improvement of adaptation skills in the social environment of the prison). The duration of this stage is determined by the effectiveness of the abovementioned methods of correction and also depends upon the duration of the terms appointed by the court. In case when steady improvement of the mental state is achieved the third stage mostly aims at the social adjustment of the persons who are ready to start their life in the society. Within this stage methods of psychotherapy, and psychological influences combined with social learning are used. 